\title{
PENGARUH DUKUNGAN ORGANISASI DAN KEADILAN IMBALAN TERHADAP KEPUASAN KERJA PADA SOPIR KOPTAX NGURAH RAI BALI
}

\author{
Ni Putu Kartika Candra Dewi ${ }^{1}$ \\ A.A. Sagung Kartika Dewi ${ }^{2}$ \\ ${ }^{1}$ Fakultas Ekonomi dan Bisnis Universitas Udayana (Unud), Bali, Indonesia \\ email: candra.user2@gmail.com
}

\begin{abstract}
ABSTRAK
Dalam sebuah organisasi, apa yang memicu seorang semangat kerja karyawan untuk bertahan dan memberikan loyalitas yang besar demi kemajuan perusahaan selalu menjadi tujuan bagi setiap perusahaan. Penelitian ini dilakukan pada Koptax Ngurah Rai Bali. Jumlah respoden yang diambil menggunakan teknik simple random sampling sebanyak 255 orang sopir taxi sebagai karyawan. Teknik analisis yang digunakan adalah regresi linier berganda. Hasil pengujian analisis dalam penelitian ini menunjukkan bahwa dukungan organisasi berpengaruh positif terhadap kepuasan kerja. Keadilan imbalan berpengaruh positif terhadap kepuasan kerja. Hasil analisis yang didapat dalam penelitian ini, maka diharapkan manajemen Koptax Ngurah Rai dapat lebih memperhatikan dukungan organisasi dan keadilan imbalan yang dialami oleh karyawan, sehingga tingkat kepuasan kerja yang dirasakan karyawan meningkat.
\end{abstract}

Kata Kunci : dukungan organisasi, keadilan imbalan, kepuasan kerja.

\begin{abstract}
In an organization, what triggers an employee morale to survive and provide great loyalty for the progress of the company has always been the goal for every company. This research was conducted on Koptax Ngurah Rai Bali. Number of respondents taken using simple random sampling technique as many as 255 taxi drivers as employees. The analysis technique used is multiple linear regression. The results of analysis testing in this study indicate that organizational support has a positive effect on job satisfaction. Justice rewards have a positive effect on job satisfaction. The results of the analysis obtained in this study, it is hoped Koptax Ngurah Rai management can pay more attention to organizational support and equity benefits experienced by employees, so that the level of job satisfaction perceived by employees increases.
\end{abstract}

Keyword : organizational support, justice rewards, job satisfaction 
Kartika Candra Dewi, Ni Putu, Pengaruh Dukungan Organisasi...

\section{PENDAHULUAN}

Studi tentang kepuasan kerja telah mendapat perhatian besar dari para peniliti dan telah menjadi topik yang sering diteliti di bidang manajemen sumber daya manusia dan perilaku organisasi (Colquitt et al., 2001). Kepusan kerja menjadi salah satu sikap karyawan yang banyak menjadi bahan penelitian yang dihubungkan dengan keadilan organisasional. Tantangan terbesar yang dihadapi oleh perusahaan adalah bagaimana mempertahankan karyawan guna berlangsungnya kegiatan operasional perusahaan. Kepuasan kerja diperlukan untuk memotivasi karyawan agar bekerja secara maksimal. Kepuasan kerja merupakan evaluasi yang menggambarkan seseorang atas perasan sikap senang atau tidak senang, puas atau tidak puas dalam bekerja (Rival \& Jauvani, 2009). Efektivitas dan produktivitas organisasi sangat di pengaruhi oleh kepuasan kerja dan ketidak puasan kerja akan menimbulkan penurunan semangat dan gairah kerja (Nitisemito, 1992).

Keadilan sangat diperlukan ditempat kerja (Ambrose, 2002) . Keadilan yang dimaksudkan pada penelitian ini adalah istilah yang digunakan untuk menggambarkan kondisi yang seimbang atau pun tidak memihak atau berat sebelah. Sementara imbalan adalah seluruh bentuk pertukaran jasa yang diberikan suatu entitas kepada pekerja. Keadilan imbalan yang dimaksud adalah kondisi yang menggambarkan keseimbangan atara kontribusi karyawan dengan apa yang diberikan oleh perusahaan dalam bentuk pertukaran jasa dengan balasan yang sesuai. Dengan kata lain keadilan imbalan yang dimaksud merupakan keadilan distributif yang masuk dalam katagori keadilan organisasional. 
Keadilan organisasional adalah perlakuan adil di tempat kerja memungkinkan secara efektif meningkatkan kepuasan kerja para anggota kelompok. (Cropanzano et al., 2007). Persoalan ketidakadilan dapat menyebabkan ketidakpuasan yang apabila tidak segera diselesaikan dapat menimbulkan perilaku menyimpang ditempat kerja. Berbagai perilaku menyimpang seperti malas bekerja, mengabaikan aturan perusahaan, atau menggunakan fasilitas perusahaan di luar kewenangannya (Aquino et al., 1999).

Menilai keadilan organisasional setidaknya terdapat tiga bidang yang harus dievakuasi, yaiu ; imbalan, proses dan hubungan interpersonal (Cropanzano et al., 2007). Keadilan organisasi dapat dibedakan ke dalam tiga komponen yaitu: keadilan distributif, keadilan prosedural, dan keadilan interaksional (Inoue et al., 2010) . Keadilan distributif (keadilan imbalan) adalah keadilan yang lebih menggambarkan mengenai alokasi sumber daya dan kesempatan, seperti misalnya upah karyawan (Lewis, 2013). Keadilan prosedural adalah persepsi keadilan terhadap prosedur yang digunakan untuk membuat keputusan sehingga setiap anggota organisasi merasa terlibat didalamnya (Budiarto \& Wardani, 2005). Keadilan interaksion al adalah persepsi individu tentang tingkat sampai mana seorang karyawan diperlakukan dengan penuh martabat, perhatian, dan rasa hormat (Robbins \& Judge, 2008).

Dukungan organisasional yang dirasakan merupakan sumber daya penting yang diperhatikan dalam pengelolaan lingkungan kerja terutama disektor jasa (Beheshtifar et al., 2013). Menurut Kambu (2012) konsep dukungan organisasional menjelaskan interaksi individu dengan organisasi yang secara 
khusus mempelajari bagaimana organisasi memperlakukan karyawannya. Dukungan organisasional yang dirasakan didefinisi sebagai persepsi karyawan mengenai sejauh mana organisasi menghargai kontribusi karyawan dan peduli tentang kesejahteraan mereka (Ucar \& Otken, 2013).

Teori yang menjadi acuan dalam dukungan organisasi adalah teori pertukaran sosial (Sosial Exchange Theory). Teori ini menggambarkan berbagai transaksi yang terjadi di seluruh kehidupan sosial seseorang yang ditandai dengan hubungan emosional yang kuat. Karyawan akan mengembangkan tingkat dukungan yang kuat dari organisasi atau pemimpin mereka, dan dapat menyebabkan perilaku kerja yang efektif, seperti kinerja yang lebih baik dan memberikan lebih banyak bantuan untuk rekan mereka (Cheung, 2013).

Organisasi Koptax Ngurah Rai beroperasi sejak tahun 1979 dengan didukung 735 karyawan yang terdiri dari 700 sopir dan 35 orang pendukung karyawan adiministrasi. Kinerja koperasi selama 5 tahun terakhir stagnan dan cenderung menurun. Menurut UU no 25 tahun 1992 menjelaskan bahwa koperasi adalah merupakan gerakan ekonomi rakyat juga sebagai badan usaha. Keduanya berperan serta untuk mewujudkan masyarakat yang maju, adil dan makmur berdasarkan Pancasila dan Undang-Undang Dasar 1945 dalam tata perekonomian nasional yang disusun sebagai usaha bersama berdasar atas asas kekeluargaan dan demokrasi ekonomi. Agar cita-cita luhur koperasi mencapai hasil sesuai visi dan misi, pemerintah dan seluruh rakyat memiliki tugas dan tanggung jawab bersama dalam membangun Koperasi. Koperasi sendiri, perlu lebih membangun dirinya 
dan dibangun menjadi kuat dan mandiri berdasarkan prinsip Koperasi sehingga mampu berperan sebagai sokoguru perekonomian nasional.

Melihat kinerja Koptax 3 tahun terakhir perkembangan organisasinya mengalami penurunan. Aset perusahaan adalah modal yang dimiliki perusahaan dalam bentuk gedung, alat bengkel, alat kantor , computer, fasilitas pendukung ( AC , Kipas Angin , TV , Kursi , Meja ), Gardu , Mesin Radio , Mesin Diesel Listrik, dll . Hal tersebut akan di buktikan melalui Tabel 1. sebagai berikut.

Tabel 1. Pencapaian Kerja Koptax Ngurah Rai Periode 2014 - 2016

\begin{tabular}{cccc}
\hline TAHUN & ASET/MODAL & REVENUE & SHU \\
\hline 2014 & Rp.1.732.392.278,55 & Rp. 678.286.650 & Rp.388.593.136,26 \\
\hline 2015 & Rp.1.746.422.699,06 & Rp. 509.040.000 & Rp.356.980.227,80 \\
\hline 2016 & Rp.1.700.678.177,82 & Rp. 480.545.000 & Rp.151.329.590,13
\end{tabular}

Sumber : Buku RAT Koperasi dan Jasa Angkutan Taxi Ngurah Rai periode 2016

Data pada Tabel 1. menunjukan hasil pencapaian kerja Koptax Ngurah Rai selama tiga tahun dari tahun 2014 sampai 2015 mengalami penurunan. Dilihat dari tabel pendapatan atau revenue, menunjukan penurunan angka yang berdampak juga pada penurunan sisa hasil usaha (SHU). Pande Sudirta selaku manager mengatakan penurunan pendapatan dan shu di sebabkan oleh munculnya pesaing baru (transportasi online) yang mencuri sebagian besar pendapatan perusahaan. Serta digunakannya sebagian modal untuk membuka layanan baru yaitu sistem online untuk menyaingi pesaing transportasi online lain.

Untuk lebih mengetahui sebab kinerja organisasi Koptax menurun, saya melakukan wawancara dengan 10 sopir taxi . 10 narasumber sopir koptax adalah I 
Ngurah Sutama, I Ketut Sukarja, I Gusti Wiantara, I Nengah Sembah, I Nengah Daging P , I Nyoman Rendiana, I Wayan Ramping, I.A Putu Adiyana, I Made Suwendi, dan I.B. Gede Yadnya.

Sopir pertama bernama I Ngurah Sutama dengan nomor lambung taxi 702 mengatakan pendapatan yang diperoleh sangat menguntungkan karena pariwisata Bali. Namun sering terjadinya kendala radio order sehingga sopir sulit menangkap informasi lokasi penumpang. Sopir merasa bebas bekerja dikarenakan peraturan dan pengawasan dari Koptax Ngurah Rai tidak terlalu ketat. Menurutnya administrasi iuran radio untuk taxi terlalu besar, apalagi pengakuan masyarakat terhadap sopir taxi menurun karena kurang displinnya sopir yang lain.

Sopir kedua I Ketut Sukarja mengatakan pendapatannya sebagai sopir taxi sehari harinya sudah lebih untuk menutup setoran yaitu 200rb/hari. Disayangkan kantor sering tutup sebelum jam seharusnya, membuat sopir rugi waktu untuk melakukan perpanjangan ijin kendaraan . Sopir mengeluhkan jumlah iuran untuk antrian lokat taxi airport terlalu besar, tidak sebanding dengan penumpang yang didapatkan. Hal tersebut membuat semakin lama armada taxi mulai sedikit.

Sopir ketiga I Gusti Wiantara mengatakan taxi adalah sumber pemasukan yang utama karena ia sudah mempunyai banyak langganan. Menurutnya proses pembuatan ijin taxi sangat mudah di bantu oleh pihak perusahaan Koptax Ngurah Rai. Menurutnya bekerja di Ngurah Rai Taxi dipandang oleh masyarakat luar sebagian besar sopir kurang disiplin / kasar.

Sopir keempat I Nengah Sembah berargumen bahwa pendapatan dari taxi menurun karena banyak pesaing baru khususnya taxi online. Meraka yang berhasil 
merebut sebagian besar penumpang kami menggunakan sistem order melalui hp . Sementara kami hanya melalui radio dimana radio juga sering kurang jelas mengeluarkan suara, membujatnya sulit untuk bekerja. Hadirnya pesaing baru tersebut seharusnya perusahaan lebih gencar lagi menyaingi transport online lain agar taxi tidak sampai di ambang kehancuran. Saat ditanyai mengenai administrasi di perusahaan, beliau menjawab sistem pelimahan peremajaan taxi baru kurang jelas dan tertata . Padahal kami sudah dengan tertib melakukan peremajaan taxi yang sampai orang luar mengatakan taxi kami selalu sebagian besar armada baru.

Sopir kelima I Nengah Daging mengatakan pendapatannya sebagai sopir sudah memuaskan terlebih ia sering mendapatkan tamu untuk tour / perjalanan jauh. Baginya kendala di lapangan adalah mencari alamat yang yang jarang di dengar atau terpelosok. Operator radio yang seharusnya membantu kurang mendukung, mereka melayani sopir dengan kurang ramah / galak saat di tanyai alamat tertentu . Enaknya di Ngurah Rai ini adalah di fasilitasi mekanik untuk pengaplikasian kendaraan oleh kantor. Yang tidak enaknya atribut operasi seperti name tag, baju harus beli terpisah, tidak di gratiskan . Nama Ngurah Rai sudah terkenal oleh masyarakat karena merupakan penyedia layanan taxi yang paling pertama.

Sopir ke-enam I Nyoman Rendiana mengeluhkan penurunan omset taxi oleh karena taxi online yang sudah semakin meluas. Fasilitas pada kendaraan taxi masih kurang menyaingi taxi online seperti GPS. Perusahaan telat bergerak dalam teknologi, disalip oleh perusahaan taxi lain yang serupa . Dirinya menyayangkan semakin lama penumpang yang didaptkan semakin sedikit, tidak menjamin untuk 
tetap menjalankan taxi selama belum ada perkembangan. Perusahaan juga mengambil tarif terlalu lebih dalam hal perpanjangan surat ijin dan surat jalan kendaraan. Walaupun yang paling pertama, masyarakat menyayangkan Ngurah Rai kalah saing dari transportasi lain yang sejenis.

Sopir ketujuh I Wayan Ramping merasakan fluktuasi penumpang taxi naik turun begitu juga dengan penadapatannya. Dirinya berharap Koptax Ngurah Rai Taxi menyediakan lagi antrian loket di tempat tempat yang ramai . Pariwisata semakin hari makin berkembang dan berpindah tempat, jadi mau tidak mau kita harus mengikuti pergeseran tersebut. Proses dan aturan kerja di Koptax Ngurah Rai mudah dan tidak ada yang menyulitkan. Sistem administrasi perusahaan menurutnya hanya perlu diseimbangkan dengan fasilitas kepada para sopir taxi. Dengan begitu masyarakat luar akan tetap menganggap ngurah rai cepat dalam penjemputan penumpang.

Sopir kedelapan A.A Putu Adiyana mengeluhkan hal yang sama pada sebagian sopir umumnya . menurunnya pendapatan mereka oleh pesaing taxi lain. Bangunan yang kurang dipermak seperti tidak diurus. Tidak adanya komisi khusus untuk sopir . Administrasi peremajaan terlalu mahal dengan pendapatan fasilitas yang kurang. Yang saat ini bisa diandalkan hanyalah nomor order yang mudah diingat masyarakat .

Sopir kesembilan I Made Suwendi mengatakan pendapatan yang direkapnya dalam mingguan dan bulanan menurun karena adanya taxi online . sarana kerja untuk sopir kalah dengan perusahaan taxi lain yang menyediakan tempat istirahat yang lengkap dan nyamab di kantor khusus sopir taxi. Menurutnya seharusnya 
perusahaan menjamin sopir bisa lebih terjangkau dalam membeli atribut kendaraan taxi . Pembayaran iuran saja tidak ada kompensasi, semua menjadi tambah minus omsetnya. Koptax Ngurah Rai sebagai taxi lokal masyarakat Bali sekaligus sebagai pelopor seharusnya menjadi contoh, ungkapnya saat diwawancarai.

Sopir terakhir I.B. Yadnya juga mengeluhkan pendapatannya dari taxi tidak bisa menutupi biaya penyusutan kendaraan, apalagi jalanan sudah semakin macet. Pelayanan fasilitas kantor juga memiliki masalah yaitu jam tutup dan buka kantor sering tidak jelas / tidak tepat waktu. Perusahaan tidak memberikan asuransi bekerja kepada sopir. Sementara untuk proses administrasi masih bisa memakai sistem kekeluargaan. Disayangkan masyarakat luar menilai Ngurah Rai Taxi kurang merespon keluhan pelanggan.

Dari hasil wawancara terungkap bahwa hambatan dalam bekerja ada 15 aspek. Aspek tersebut adalah adanya pesaing taxi sejenis, pesaing taxi online , pelayanan, kondisi kantor, kelengkapan fasilitas , sistem administrasi , nama baik perusahaan, pendapatan, peraturan perusahaan , kondisi kerja , loket antrian , proses kerja, jaminan kerja, keamanan kerja, dan kompensasi perusahaan. Keseleruhan hasil wawancara akan dituangkan dalam tabel rekapitulasi pada Tabel 2. 
Tabel 2 Rekapitulasi Hasil Wawancara Sopir Koptax Ngurah Rai

\begin{tabular}{|c|c|c|c|}
\hline \multicolumn{4}{|c|}{ REKAPITULASI HASIL WAWANCARA SOPIR TAXI NGR } \\
\hline NO & JENIS ASPEK & $\begin{array}{c}\text { JUMLAH } \\
\text { ASPEK }\end{array}$ & PERSENTASE \\
\hline 1 & Pesaing Taxi Sejenis & 2 & 4 \\
\hline 2 & Pesaing Taxi Online & 4 & 8 \\
\hline 3 & Pelayanan & 5 & 10 \\
\hline 4 & Kondisi Kantor & 3 & 6 \\
\hline 5 & Kelengkapan Fasilitas & 3 & 6 \\
\hline 6 & Loket Antrian & 2 & 4 \\
\hline 7 & Proses Kerja & 3 & 6 \\
\hline 8 & Jaminan Kerja & 2 & 4 \\
\hline 9 & Administrasi Perusahaan & 5 & 10 \\
\hline 10 & Nama Baik Perusahaan & 5 & 10 \\
\hline 11 & Pendapatan & 7 & 14 \\
\hline 12 & Kompensasi & 3 & 6 \\
\hline 13 & Keamanan Kerja & 2 & 4 \\
\hline 14 & Aturan Perusahaan & 2 & 4 \\
\hline 15 & Kondisi Kerja & 2 & 4 \\
\hline & TOTAL : & 50 & 100 \\
\hline
\end{tabular}

Sumber : hasil wawancara 10 responden sopir taxi

Tabel 2 menjelaskan bahwa terdapat 15 jenis aspek hasil wawancara yang diantaranya menunjukan jumlah yang sama antar pendapat sopir taxi. Aspek dengan jumlah terbanyak yaitu pendapatan berjumlah 7 dengan persentase $14 \%$, dan hasil terakhir dengan jumlah paling sedikit yaitu $4 \%$ adalah aspek loket antrian , jaminan kerja , keamanan kerja , peraturan perusahaan , dan kondisi kerja.

15 aspek hasil wawancara menunjukkan pendapat sopir taxi selama bekerja di Koptax Ngurah Rai Bali . Pendapat 10 sopir taxi tersebut menunjukkan ketidak puasan yang disebabkan oleh pendapatan sopir taxi yang menurun dari sebelumnya muncul pesaing taxi online. 
Menurut Sutrisno (2012) kepuasan kerja karyawan merupakan masalah penting yang diperhatikan dalam hubungannya dengan produktivitas kerja karyawan dan ketidakpuasan sering dikaitkan dengan tingkat tuntutan dan keluhan pekerjaan yang tinggi.

Berdasarkan UU no 13 tahun 2003 pasal 88 setiap pekerja/ buruh berhak mendapatkan penghasilan berdasarkan upah minimum regional . mengacu kepada Peraturan Pemerintah (PP) No.78/2015 tentang Pengupahan standart UMR provinsi Bali sebesar Rp. 1,956,727,-- . Hal tersebut menjadi acuan sopir taxi dalam mendapatkan penghasilan tiap bulannya.

Responden I Nengah Sembah mengatakan sebelum adanya taxi online pendapatan bersih perbulannya selama menjadi sopir taxi bisa mencapai 3 sampai 4 juta rupiah. Namun semenjak 3 tahun terakhir munculnya taxi online pendapatannya menjadi turun drastis sebesar 1,2 juta sampai 1,6 juta perbulannya dimana jumlah tersebut sudah termasuk di bawah UMR. Oleh karena itu dirinya sempat mengikuti demo para sopir taxi dikarenakan perusahaan tidak bergerak cepat menanggapi perubahan kondisi yang sangat berpengaruh terhadap kehidupan para anggotanya.

Sopir taxi lain I Nyoman Rendiana juga merasakan penurunan pendapatan oleh karena pesaing taxi online. Hal tersebut membuat beliau dan rekanrekannya yang lain menjadi tidak semangat bekerja dan berkeinginan untuhk pindah menjadi sopir taxi online. Penyebab tersebut dikarenakan beban yang telah dikeluarkan seperti biaya kendaraan beserta surat ijin taxi, tenaga, serta waktu tidak sepadan dengan pengahsilan yang di dapatkannya. Tidak hanya penghasilan 
di bawah UMR tetapi tenaga dan waktu yang membuat para sopir harus bekerja lebih dari 8 jam kerja demi mengejar target.

Berdasarkan penelitian yang dilakukan Eisenberger et al. (1986) bahwa pegawai menganggap kerja adalah suatu bentuk pertukaran dengan kebutuhankebutuhannya sehingga mereka selalu melakukan penilaian apakah organisasi mempunyai perhatian terhadap segala jerih payah yang telah disumbangkan dan mampu memberikan imbalan yang memadai, atau dengan kata lain, jika pegawai bekerja secara ekstra, apakah organisasi akan memberikan imbalan yang lebih atau tidak.

Permasalahan yang terdapat di Koptax Ngurah Rai Bali dilihat dari hasil wawancara 10 Responden menjelaskan aspek- aspek mendukung yang dimaksud adalah organisasi memperhatikan kesejahteraan anggota, kondisi kerja menyenangkan, pemberian fasilitas, sistem reward, kontribusi, dimana aspek tersebut akan memotivasi anggota sehingga tercipta suatu kepuasan kerja.

John Stacey Adams (1965), ahli psikologi perilaku dan tempat kerja, berasumsi bahwa pada dasarnya manusia menyenangi perlakuan yang adil/sebanding, berhubungan dengan kepuasan relasional dalam hal persepsi distribusi yang adil/tidak adil dari sumber daya dalam hubungan interpersonal. Dengan kata lain, kita menginginkan keadilan (yaitu, kita ingin merasa bahwa ketika kita mengorbankan sesuatu, kita diperlakukan secara adil dan organisasi membayar dengan pengorbanan yang sesuai).

Dari 10 Responden mengatakan organisasi seharusnya memperlakukan sopir dengan adil. Sebagian besar merka merasakan jerih payahnya tidak 
sebanding dengan apa yang merka dapatkan, baik itu secara ekstrinsik maupun intrinsik. Keadilan secara eksternal yang diinginkan sopir taxi adalah pendapatannya tidak sebanding dengan pendapatan taxi online. Sementara dari keadilan internal iuran dan pembiayaan sopir selaku anggota tidak sebanding dengan fasilitas yang didapatkannya. Dengan kata lain parusahaan tidak memaksimalkan pelayanan demi kesejahteraan anggota.

Kedua keadilan tersebut sangat berpengaruh terhadap kinerja sopir taxi. Jika keadilan bersifat positif maka kepuasan kerja sopir akan tercipta , sebaliknya jika keadilan itu negative maka akan menimbulkan ketidak puasaan sopir taxi yang akan memunculkan minat mlas kerja dan minat untuk keluar. Berdasarkan hasil diatas seluruh masalah terkait kepuasan kerja sopir dengan, tingkat permasalahan paling besar berada pada pendapatan sopir taxi. Oleh karena itu penulis tertarik untuk menguji pengaruh dukungan organisasi dan keadilan imbalan di Koptax Ngurah Rai Bali.

Tujuan yang ingin di capai dalam penelitian ini adalah untuk menguji dukungan organisasi dan keadilan imbalan sopir koperasi dan jasa angkutan taxi Ngurah Rai Bali dengan kepuasan kerja sopir taxi.

Teori Dua Faktor yang juga dikenal sebagai Teori Motivasi Herzberg atau teori hygiene-motivator. Teori ini dikembangkan oleh Frederick Irving Herzberg (2000), seorang psikolog asal Amerika Serikat. Ia dianggap sebagai salah satu pemikir besar dalam bidang manajemen dan teori motivasi.

Frederick Herzberg menyatakan bahwa ada faktor-faktor tertentu di tempat kerja yang menyebabkan kepuasan kerja, sementara pada bagian lain ada pula 
faktor lain yang menyebabkan ketidakpuasan. Dengan kata lain kepuasan dan ketidakpuasan kerja berhubungan satu sama lain.

Teori pertukaran sosial atau sosial exchange teory dimana hubungan antara pegawai dan organisasinya adalah merupakan suatu hubungan pertukaran, misalnya suatu pegawai mau bekerja disuatu organisasi karena pegawai tersebut hendak mempertukarkan usaha dan loyalitasnya dengan imbalan material sosioemosional tertentu.

Teori Pertukaran Sosial adalah salah satu teori sosial yang mempelajari bagaimana seseorang berhubungan dengan orang lain, kemudian seseorang itu menentukan keseimbangan antara pengorbanan dan keuntungan yang didapatkan dari hubungan itu. Setelah seseorang menentukan keseimbangannya, ia akan menentukan jenis hubungan dan kesempatan memperbaiki hubungan atau tidak sama sekali.

Teori pertukaran sosial ini juga digunakan untuk menjelaskan berbagai penelitian mengenai sikap dan perilaku dalam ekonomi (Theory of Economic Behaviour). Selain itu, teori ini juga digunakan dalam penelitian komunikasi, misalnya dalam konteks komunikasi interpersonal, kelompok dan organisasi. Oleh karena itu, teori pertukaran sosial ini, selain menjelaskan mengenai sikap dalam ekonomi, juga menjelaskan mengenai hubungan dalam komunikasi.

John Stacey Adams, ahli psikologi perilaku dan tempat kerja, yang menerbitkan Teori Ekuitas (Kesetaraan) pada motivasi kerja pada tahun 1963. Teori ini berasumsi bahwa pada dasarnya manusia menyenangi perlakuan yang adil/sebanding, berhubungan dengan kepuasan relasional dalam hal persepsi 
distribusi yang adil/tidak adil dari sumber daya dalam hubungan interpersonal. Dengan kata lain, kita menginginkan keadilan (yaitu, kita ingin merasa bahwa ketika kita dibandingkan dengan orang lain, kita diperlakukan secara adil dan organisasi tidak berpihak kepada siapapun).

Model Ekuitas untuk mengukur situasi motivasi yang akan digunakan tidak tergantung pada sejauh mana seseorang percaya akan mendapatkan imbalan yang melebihi usahanya. Sebaliknya, Ekuitas, dan rasa keadilan yang biasanya mendasari motivasi, bergantung pada perbandingan antara rasio imbalan / investasi rasio dengan rasio kenikmatan (atau derita) yang dialami oleh orang lain yang berada dalam situasi yang mirip atau sama.

Menurut Adams (1965), ketidakadilan menciptakan ketegangan sebanding dengan ketidakseimbangan. Ini adalah ketegangan yang memotivasi individu untuk mengurangi kesenjangan tersebut. Akibatnya, semakin tinggi perasaan ketidakadilan, semakin kuat motivasi untuk mengurangi itu.

Teori keseimbangan berfokus pada rasio input-output dalam organisasi. Input diwakili oleh kontribusi kita terhadap organisasi; output segala sesuatu yang kita terima dari organisasi. Teori ini mengasumsikan bahwa ketika kita terlibat dalam hubungan pertukaran dengan organisasi, dan mengevaluasi keadilan dari apa yang kita dapatkan dari pertukaran ini dengan membandingkan rasio inputoutput kita sendiri dengan yang lain, untuk menentukan apakah kita dibayar kurang/underpaid atau dibayar lebih.

Hipotesis merupakan jawaban sementara terhadap rumusan masalah penelitian, oleh karena itu rumusan masalah penelitian biasanya disusun dalam 
bentuk kalimat pertanyaan. Dikatakan sementara, karena jawaban yang diberikan baru didasarkan pada teori yang relevan, belum didasarkan fakta-fakta empiris yang diperoleh melalui pegumpulan data (Sugiyono, 2014:93).

Apri \& Mariaty (2016) menyatakan bahwa fasilitas kerja berpengaruf positif dan signifikan terhadap kepuasan kerja. Gita S. (2014) menyatakan sarana kerja berpengaruh positif dan signifikan terhadap kepuasan kerja pegawai. Kambu dkk. (2012) menunjukkan bahwa dukungan organisasi berpengaruh positif dan signifikan terhadap kepuasan kerja. Miao (2011) dalam penelitiannya berjudul; Perceived organizational support, job satisfaction, task performance and Organizational Citizenship Behavior in china menemukan hasil bahwa terdapat hubungan positif antara Persepsi dukungan organiasi terhadap kepuasan kerja dalam indkator $O C B$ seperti: helping, civic virtue, conscientiousness, and courtesy. Mangun J. (2012) mengatakan bahwa terdapat hubungan yang positif dan signifikan antara dukungan organisasi dengan kepuasan kerja. Puspita Sari (2014) dengan penelitian terhadap Persepsi dukungan Organisasi , Kepuasan kerja mengungkapkan bahwa persepsi dukungan organisasi memiliki pengaruh yang signifikan terhadap $O C B$ dalam indikator kepuasan kerja, yang berarti bahwa peningkatan persepsi dukungan organisasi mampu meningkatkan kepuasan kerja . $\mathrm{H}_{1}$ : Dukungan organisasi berpengaruh positif dan signifikan terhadap kepuasan kerja karyawan.

Menurut Tang et al. (1996) menyatakan bahwa keadilan distributif secara signifikan berhubungan dengan kepuasan. Menurut Lambert (2013) lebih banyak studi mengklaim bahwa keadilan distributif memiliki pengaruh kuat pada 
kepuasan kerja dari pada keadilan prosedural. Hal yang sama dikemukakan oleh Cohen-Carash \& Spector (2001) yang menyatakan bahwa keadilan distributif merupakan predictor yang paling kuat bagi kepuasan kerja disbanding prosedural dan interaksional. Penelitian lain yang menghasilkan signifikansi pengaruh keadilan distributif terhadap kepuasan kerja adalah Nadiri \& Tanova (2010). Bun Eny L. \& Heru K. (2012) mengungkapkan hasil penelitiannya diketahui keadilan distributif berpengaruh positif signifikan terhadap kepuasan kerja perawat di RSUD Sultan Immanudin Pangkalan. Dengan demikian semakin adil imbalan yang diberikan maka cenderung dapat meningkatkan Kepuasan Kerja.

$\mathrm{H}_{2}$ : Keadilan distributif berpengaruh positif dan signifikan terhadap kepuasan kerja.

Gambar 1. Kerangka Konseptual

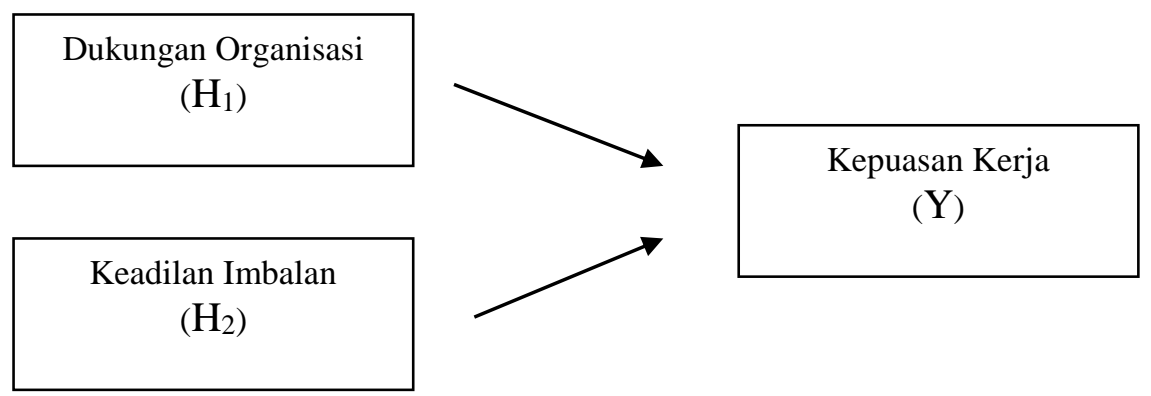

Sumber : Apri \& Mariaty (2016); Gita S. (2014); Kambu dkk. (2012); Miao (2011); Mangun J. (2012); Puspita Sari (2014).

\section{METODE PENELITIAN}

Pendekatan yang akan digunakan untuk meneliti sumber masalah pada penelitian ini adalah pendekatan kuantitatif yang berbentuk asosiatif karena 
penelitian ini bertujuan untuk mengetahui hubungan antara dua variabel atau lebih. Menurut Sugiyono (2014:13), metode penelitian kuantitatif dapat diartikan sebagai metode penelitian yang berlandaskan pada filsafat positivism, digunakan untuk meneliti pada populasi atau sampel tertentu, analisis data bersifat kuantitatif/statistik dengan tujuan untuk menguji hipotesis yang telah ditetapkan.

Penelitian ini dilakukan pada Koperasi dan Jasa Angkutan Taxi Ngurah Rai Bali yang beralamat J1. Brigjen Ngurah Rai No.702 Pesanggaran. Objek penelitian adalah sifat dari objek yang diterapkan peneliti untuk dipelajari dan kemudian memperoleh kesimpulan (Sugiyono, 2014). Objek dalam penelitian ini adalah kepuasan kerja sopir taxi pada Koptax Ngurah Rai Bali yang dipengaruhi oleh dukungan organisasi dan keadilan imbalan.

Populasi merupakan wilayah generalisasi yang terdiri atas objek atau subjek yang mempunyai kualitas dan karakteristik tertentu yang ditetapkan oleh peneliti untuk dipelajari dan kemudian ditarik kesimpulannya (Sugiyono, 2014). Populasi adalah keseluruhan subyek penelitian 700 orang. Populasi dalam penelitian ini adalah seluruh sopir taxi Koptax Ngurah Rai Bali.

Model analisis yang digunakan untuk menyelesaikan permasalahan penelitian ini adalah regresi linier berganda.Permaslahan yang harus dijawab adalah variabel bebas (Dukungan organissi dn Keadilan Imbalan) berpengaruh secara simultan, secara parsial, dan dominan terhadap variabel terikat (Kepuasan Kerja). Analisis selanjutnya digunakan SPSS 15.0. Model regresi linier berganda sebagai berikut (Suyana, 2007:77) : 
$Y=a+\beta_{1} X_{1}+\beta_{2} X_{2}+e$

Keterangan:

$$
\begin{array}{ll}
\mathrm{Y} & =\text { Kepuasan Kerja } \\
\mathrm{a} & =\text { Konstanta } \\
\beta & =\text { Koefisien regresi } \\
\mathrm{X}_{1} & =\text { Dukungan Organisasi } \\
\mathrm{X}_{2} & =\text { Keadilan Imbalan } \\
\mathrm{e} & =\text { Kesalahan residual (error) }
\end{array}
$$

\section{HASIL DAN PEMBAHASAN}

Pengujian data dalam penelitian ini menggunakan teknik analisis regresi linier berganda. Tahapan melakukan teknik analisis regresi linier berganda yaitu : Perhitungan koefisien regresi linier berganda dilakukan dengan analisis regresi melalui software SPSS 18.0 for Windows, diperoleh hasil yang ditunjukan pada Tabel 3 berikut :

Tabel 3 Hasil Analisis Regresi Linier Berganda

\begin{tabular}{lrrr}
\hline \multicolumn{1}{c}{ Variabel } & $\begin{array}{c}\text { Nilai Koefisien } \\
\text { Regresi }\end{array}$ & t hitung & $\begin{array}{c}\text { Nilai } \\
\text { Signifikansi }\end{array}$ \\
\hline \multicolumn{1}{c}{ Dukungan Organisasi $\left(\mathrm{X}_{1}\right)$} & 0,165 & 3,036 & 0,003 \\
\hline \multicolumn{1}{c}{ Keadilan Distributif $\left(\mathrm{X}_{2}\right)$} & 0,607 & 11,192 & 0,000 \\
\hline R Square & & & 0,513 \\
Adjusted R Square & & & 0,509 \\
F Statistik & & & 132,760 \\
Signifikansi & & 0,000 \\
\hline
\end{tabular}

Sumber : Lampiran

Berdasarkan hasil analisis regresi linier berganda seperti yang disajikan pada Tabel, maka persamaan strukturalnya adalah sebagai berikut :

$$
Y=\beta_{1} X_{1}+\beta_{2} X_{2}+e
$$




$$
\mathrm{Y}=0,165 \mathrm{X} 1+0,607 \mathrm{X} 2+\mathrm{e}
$$

\section{Nilai Koefisien Determinasi}

Nilai determinasi total sebesar 0,509 mempunyai arti bahwa sebesar 50,9\% variasi kepuasan kerja dipengaruhi oleh variasi dukungan organisasi, dan keadilan distributif, sedangkan sisanya sebesar 49,1\% dijelaskan oleh faktor lain yang tidak dimasukkan ke dalam model.

Uji asumsi klasik dilakukan dengan tujuan untuk memastikan hasil yang diperoleh memenuhi asumsi dasar di dalam analisis regresi. Hasil uji asumsi klasik yang dilakukan dalam penelitian ini adalah uji normalitas, uji multikoliniearitas, uji autokorelasi dan uji heteroskedastisitas. Hasil dari uji asumsi klasik yang diolah dengan bantuan software SPSS 18.0 disajikan sebagai berikut:

\section{Uji Normalitas}

Uji ini bertujuan untuk mengetahui apakah residual dari model regresi yang dibuat berdistribusi normal atau tidak. Untuk menguji apakah data yang digunakan normal atau tidak dapat dilakukan dengan menggunakan uji Kolmogorov Sminarnov. Apabila koefisien Asymp. Sig. (2-tailed) lebih besar dari 0,05 maka data tersebut dikatakan berdistribusi normal.

\section{Tabel 4 Hasil Uji Normalitas}

\begin{tabular}{cc}
\hline & Unstandardized Residual \\
\hline $\mathrm{N}$ & 255 \\
\hline Kolmogorov-Smirnov $Z$ & 1,037 \\
\hline Asymp.Sig.(2-tailed) & 0,233 \\
\hline Sumber : Lampiran &
\end{tabular}


Berdasarkan Tabel 4 dapat dilihat bahwa nilai Kolmogorov Sminarnov (KS) sebesar 1,037, sedangkan nilai Asymp. Sig. (2-tailed) sebesar 0,233. Hasil tersebut mengindikasikan bahwa model persamaan regresi tersebut berdistribusi normal karena nilai Asymp. Sig. (2-tailed) 0,233 lebih besar dari nilai alpha 0,05.

Uji Multikoleniaritas

Uji ini bertujuan untuk menguji apakah pada model regresi ditemukan adanya korelasi antar variabel bebas. Adanya multikolinearitas dapat dilihat dari nilai tolerance atau variance inflation factor (VIF). Jika nilai tolerance lebih dari $10 \%$ atau VIF kurang dari 10, maka dikatakan tidak ada multikolinearitas.

Tabel 5 Hasil Uji Multikoleniaritas

\begin{tabular}{ccc}
\hline Variabel & Tolerance & VIF \\
\hline Dukungan Organisasi $\left(\mathrm{X}_{1}\right)$ & 0,656 & 1,523 \\
\hline Keadilan Distributif $\left(\mathrm{X}_{2}\right)$ & 0,656 & 1,523 \\
\hline
\end{tabular}

Sumber : Lampiran

Berdasarkan Tabel 5 dapat dilihat bahwa nilai tolerance dan VIF dari seluruh variable menunjukkan bahwa nilai tolerance untuk setiap variabel lebih besar dari $10 \%$ dan nilai VIF lebih kecil dari 10 yang berarti model persamaan regresi bebas dari multikolinearitas.

Uji Heteroskedastisitas

Uji ini bertujuan untuk mengetahui apakah dalam model regresi terjadi ketidaksamaan varians dari residualsatu pengamatan ke pengamatan lainyang dilakukan dengan uji Glejser.Jika tidak ada satu pun variabel bebas yang berpengaruh signifikan terhadap nilai absolute residual atau nilai signifikansinya di atas 0,05 maka tidak mengandung gejala heteroskedastisitas. 
Tabel 6 Hasil Uji Heteroskedastisitas

\begin{tabular}{|c|c|c|c|c|c|}
\hline \multirow[t]{2}{*}{ Model } & \multicolumn{2}{|c|}{$\begin{array}{c}\text { Unstandardized } \\
\text { Coefficients } \\
\end{array}$} & \multirow{2}{*}{$\begin{array}{c}\begin{array}{c}\text { Standardized } \\
\text { Coefficients }\end{array} \\
\text { Beta }\end{array}$} & \multirow[b]{2}{*}{$\mathrm{T}$} & \multirow[b]{2}{*}{ Sig. } \\
\hline & $B$ & $\begin{array}{l}\text { Std. } \\
\text { Error }\end{array}$ & & & \\
\hline 1 (Constant) & .525 & .028 & & 18.426 & .000 \\
\hline $\begin{array}{l}\text { Dukungan } \\
\text { Organisasi }\end{array}$ & -.003 & .035 & -.008 & -.098 & .922 \\
\hline Keadilan Distributif & -.065 & .035 & -.143 & -1.858 & .064 \\
\hline
\end{tabular}

Pada Tabel 6 dapat dilihat bahwa nilai Sig. dari variabel dukungan organisasi, dan keadilan distributif, masing-masing sebesar 0,922 dan 0,064 Nilai tersebut lebih besar dari 0,05 yang berarti tidak terdapat pengaruh antara variabel bebas terhadap absolute residual. Dengan demikian, model yang dibuat tidak mengandung gejala heteroskedastisitas.

Hasil pengujian hipotesi diperoleh bahwa terdapat pengaruh Dukungan Organisasi yang positif dan signifikan terhadap Kepuasan Kerja pada sopir Koptax Ngurah Rai, dengan demikian dapat dijelaskan bahwa semakin tinggi Dukungan Organisasi maka Kepuasan Kerja akan semakin tinggi dirasakan, dan sebaliknya semakin rendah Dukungan Organisasi maka akan berdampak pada penurunan Kepuasan Kerja yang dirasakan. Hasil yang signifikan ini disebabkan oleh fasilitas yang digunakan sopir untuk bekerja membuat sopir merasa nyaman dan aman dalam melakukan pekerjaan sehingga dari perasaan nyaman dan aman tersebut menimbulkan kepuasan kerja.

Hasil penelitian ini mengembangkan penelitian yang dilakukan oleh Apri \& Mariaty (2016) menyatakan bahwa fasilitas kerja berpengaruf positif dan signifikan terhadap kepuasan kerja. Gita S. (2014) menyatakan sarana kerja 
berpengaruh positif dan signifikan terhadap kepuasan kerja pegawai. Kambu dkk. (2012) menunjukkan bahwa dukungan organisasi berpengaruh positif dan signifikan terhadap kepuasan kerja. Miao (2011) dalam penelitiannya berjudul; Perceived organizational support, job satisfaction, task performance and Organizational Citizenship Behavior in china menemukan hasil bahwa terdapat hubungan positif antara Persepsi dukungan organiasi terhadap kepuasan kerja dalam indkator $O C B$ seperti: helping, civic virtue, conscientiousness, and courtesy. Mangun J. (2012) mengatakan bahwa terdapat hubungan yang positif dan signifikan antara dukungan organisasi dengan kepuasan kerja. Puspita Sari (2014) dengan penelitian terhadap Persepsi dukungan Organisasi , Kepuasan kerja mengungkapkan bahwa persepsi dukungan organisasi memiliki pengaruh yang signifikan terhadap $O C B$ dalam indikator kepuasan kerja, yang berarti bahwa peningkatan persepsi dukungan organisasi mampu meningkatkan kepuasan kerja .

Hasil pengujian hipotesi diperoleh bahwa terdapat pengaruh Keadilan Imbalan yang positif dan signifikan terhadap Kepuasan Kerja pada sopir Koptax Ngurah Rai, dengan demikian dapat dijelaskan bahwa semakin tinggi Keadilan Imbalan maka Kepuasan Kerja akan semakin tinggi dirasakan, dan sebaliknya semakin rendah Keadilan Imbalan maka akan berdampak pada penurunan Kepuasan Kerja yang dirasakan. Hasil yang signifikan ini disebabkan oleh keadilan yang dirasakan sopir sepadan dengan jerih payah yang mereka keluarkan. Seperti halnya keadilan yang diharapkan adalah keadilan imbalan / distributif dimana pendapatan mereka sudah layak, sudah sesuai standart UMK seperti pekerja lain pada umumnya serta sebanding dengan prestasi kerja mereka. Semua 
hal tersebut akan menciptakan kepuasaan kerja karyawan dan menciptakan semangat kerja karyawan untuk memajukan perusahaan.

Hasil penelitian ini mengembangkan penelitian yang dilakukan oleh Tang et al. (1996) menyatakan bahwa keadilan distributif secara signifikan berhubungan dengan kepuasan. Menurut Lambert (2013) lebih banyak studi mengklaim bahwa keadilan distributif memiliki pengaruh kuat pada kepuasan kerja dari pada keadilan prosedural. Hal yang sama dikemukakan oleh Cohen-Carash \& Spector (2001) yang menyatakan bahwa keadilan distributif merupakan predictor yang paling kuat bagi kepuasan kerja disbanding prosedural dan interaksional. Penelitian lain yang menghasilkan signifikansi pengaruh keadilan distributif terhadap kepuasan kerja adalah Nadiri \& Tanova (2010). Bun Eny L. \& Heru K. (2012) mengungkapkan hasil penelitiannya diketahui keadilan distributif berpengaruh positif signifikan terhadap kepuasan kerja perawat di RSUD Sultan Immanudin Pangkalan. Dengan demikian semakin adil imbalan yang diberikan maka cenderung dapat meningkatkan Kepuasan Kerja.

\section{SIMPULAN DAN SARAN}

Berdasarkan hasil analisis dan pembahasan dapat diambil simpulan yaitu sebagai berikut. Dukungan Organisasi memiliki pengaruh positif dan signifikan terhadap Kepuasan Kerja. Artinya bahwa karyawan yang merasakan Dukungan Organisasi akan bisa bekerja dengan baik karena fasilitas serta kontribusi perusahaan yang membuat karyawan merasa nyaman dan aman memicu semangat kerja karyawan bertambah dan membuat karyawan bertahan pada perusahaan tersebut dalam jangka waktu yang lama. Hal ini menunjukkan bahwa semakin 
tinggi dukungan organisasi yang terjadi di perusahaan maka semakin tinggi juga kepuasan kerja pada karyawan. Keadilan Imbalan memiliki pengaruh positif dan signifikan terhadap Kepuasan Kerja Artinya bahwa semakin tinggi Keadilan yang dirasakan karyawan saat bekerja maka semakin tinggi kepuasan yang mereka rasakan sehingga karyawan berfikir untuk bertahan di dalam perusahaan dalam jangka waktu yang lama. Hal ini menunjukkan bahwa semakin tingginya keadilan yang disebabkan oleh pemenuhan kontribusi yang sesuai maka tingkat Kepuasan kerja juga akan semakin tinggi.

Kepuasan Kerja dapat diperhatikan oleh perusahaan dengan mengutamakan dukungan organisasi dan keadilan imbalan pada sopir Koptax Ngurah Rai, terutama pada fasilitas kerja karyawan untuk bekerja dan menghargai usaha karyawan dengan memmberikan apresiasi yang sepadan agar seluruh sopir bisa merasakan kenyamanan dan keamanan dalam bekerja. Agar tidak menjadi beban kerja yang dapat menyebabkan tekanan pada karyawan yang berujung pada mengundurkan diri.

Hal yang harus diperhatikan Koptax Ngurah Rai untuk meningkatkan Kepuasan Kerja pada karyawannya yaitu dengan cara tidak memberikan tekanan pekerjaan yang sulit dengan aturan yang membuat sopir merasa tidak leluasa dalam bekerja. Terus memperhatikan kebijakan agar nyaman bagi karyawan maupun perusahaan dan menjaga agar lingkungan kerja yang tetap kondusif, atasan terus perhatian dan mengevaluasi atas pekerjaan yang diberikan pada karyawan, memberikan kontribusi yang sepadan, mendengarkan permasalahan yang karyawan hadapi sebelum membuat keputusan kerja, dapat menerima 
masukan dari bawahan, memperhatikan hak dan kebutuhan karyawan dan mengurangi kejenuhan karyawan yang dapat dilakukan dengan cara mengajak karyawan untuk berekreasi.

Kepada peneliti selanjutnya agar lebih memperluas sampel penelitian dengan meneliti pada perusahaan yang berbeda seperti perhotelan, BUMN, perbankan dan UMKM. Selain itu peneliti selanjutnya diharapkan dapat menambahkan variabel lain terkait Kepuasan Kerja seperti OCB dan Kepemimpinan serta dapat juga menambahkan variable lain sebagai mediasi ataupun moderasi.

\section{REFERENSI}

Adams, J.S. 1963. Toward An Understanding Of Inequity. Journal Of Abnormal \& Social Psychology, 67(5): h: $422-436$

Alkerdawy, M. M. A. 2014. The Mediating Effects of Duty Orientation on the Relationship between Perceived Organizational Support and Organizational Citizenship Behavior in the Public Banks of Egypt. International Journal of Business and Management,2(2): h: 136-145.

Al-Zu'bi, H.A. 2010. A Study Of Relationship Between Organizational Justice And Job Satisfaction. International Journal of Business and Management 5(12): h: $102-109$.

Antoncic, J.A. \& Antoncic, B. 2011. Employee Satisfaction Intrapreneurship And Firm Growth : A Model. Industrial Management And Data Systems, 111(4): h: $589-607$.

Ambrose, M.L. \& Arnaud, A. 2002. Are Procedural Justice And Distributive Justice Conceptually Distinct ?, Handbook Of Organizational Justice. Lawrence Erlbaum Associates, Inc.

Apri, H , dan , Mariati, K. 2016 . Perbandingan Equity Theory, Goal Setting Theory, Dan Expectancy Theory; Tinjauan Psikologi Kognitif. Universitas Muhammadiyah Yogyakarta 
Ardi, R.T.B, dan Sudarma, K. 2015. Pengaruh Persepsi Dukungan dan Keadilan Organisasi Terhadap OCB dengan kepuasan Kerja sebagai variable intervening. Management analysis Journal,1(4): h: 46-60

Aris,Y., K., dan Made, S. P. 2014 . Pengaruh Organizational Justice serta Job Insecurity terhadap Job Satisfaction Pegwai Kontrak pada PT. Wico Interna, Singaraja- Bali. Jurnal Manajemen Strategi Bisnis dan Kewirausahaan, 8(1): h: 52-68.

Baheshtifar, 2013. Organizational Justice Perceptions As Predictor Of Job Satisfaction And Organization Commitment. International Journal Of Business And Management, 4(9): h: 145-154

Boles, et al. 1951. An Index Of Job Satisfaction. Journal Of Applied Psychology, 35(5): h: $307-311$.

Budiarto, Imam, dan Wardani. 2008. Structural Equation Modeling : Metode Alternatif Dengan Partial Least Square. Semarang : Badan Penerbit Universitas Diponegoro.

Cheung, M. F. Y. \& Wu, W-P. 2013. Leader-Member Exchange \& Employee Work Outcomes In Chinese Firms: The Mediating Role Of Job Satisfaction. Asia Pacific Business Review 18(1): h: 65 - 81 .

Colquitt, J.A., Wesson, M.J., Porter, C.O.L.H., Conlon, D.E., \&Ng, K.Y. 2001. Justice At The Millenium : A Meta-Analytic Review Of 25 Years Of Organizational Justice Research. Journal Of Applied Psychology, 86(3): h: $425-445$.

Cropanzano, R., Bowen, D.E., \& Gilliland, S.W. 2007. The Management Of Organizational Justice. Academy Of Management Perspectives, 21(4): h: 34 -38 .

Eisenberger, R.; Stinglhamber, F; Vandenberghe, C.; Sucharski, I.L.; dan Rhoades, L. (2002). Perceived Suppervisor Support: Contributions to Perceived Organizational Support and Employee Retention. Journal of Applied Psychology, 87(3): h: 565-571

Fakultas Ekonomi Universitas Udayana, 2017. Pedoman Pembuatan Skripsi. Penerbit: Fakultas Ekonomi Universitas Udayana.

Filipova. 2011. Relationship Among Ethical Climates Perceived Organzatonal Support And Intent To Leave For Licensed Nurses And Skilled Nursing Facilities. International Journal Of Business and Management,5(2): h: 136-140. 
Flint, Douglas H. and Lynn M Haley. (2013). Distributive Justice in Human Resource Management: A Multisystem Approarch. Journal Of American Business Review, 2(1): h: 50-57

Foley. 2015. The Effect of Perceived Organizational Support and Job Satisfaction on Transfer Training. Indian Journal Of Science And Technology

Ghozali, Imam. (2015). Aplikasi Analisis Multivariate Dengan Program IBM SPSS 19. Semarang: Badan Penerbit Universitas Diponegoro.

Gita, S. 2014. Structural Equation Modeling. Jakarta : Salemba Infotek.

Greenberg J. \& Baron RA., 1996 Behavior in Organizations: Understanding \& Managing The Human Side of Work, Prentice Hall International Inc. International Journal Of Business and Management, 3(5): h: 126-130.

Handoko, T. Hani. 2013 Manajemen Personalia dan sumber Daya Manusia. Edisi kedua. Yogyakarta:BPFE Jogjakarta.

Hasibuan, Malayu S.P. 2010.Manajemen Sumber Daya Manusia. Jakarta: Penerbit Bumi Aksara.

Herzberg,F., 1968. One More Title : Haw doyou motivate employes? Harvad Bussines Review Journal (Januari-February), 4(6): h: 53-63.

Husaini, K, dan , Purnomo , J . 2016. Seri Manajemen Sumber Daya Manusia: Memotivasi Pegawai. PT. Gramedia Asri Media : Jakarta

Inove. \& Vodanovich, S. J. 1995. A Field Study Of Distributive \& Procedural Justice As Predictors Of Satisfaction \& Organizational Commitment. Journal Of Business \& Psychology, 10(1): h: 99 - 114.

Kambu, 2012. Pengaruh Keadilan Organisasional terhadap kepuasan kerja dan dampaknya terhadap komitmen, Dan Intensi Keluar di PT Indonesia Power UPB Bali. E-Jurnal Ekonomi dan Bisnis Universitas Udayana, 3(06): h: 308-329.

Kim, Sangmook. 2006. Public Service Motivation and Organizational Citizenship Behavior in Korea. International Journal of Manpower 27(8): h: 689700.

Koperasi Jasa Angkutan Taxi Ngurah Rai Bali, 2016. Laporan Pertanggungjawaban Pengurus dan Laporan Hasil Pemeriksaan Pengawas.Denpasar : Koperasi Jasa Angkutan Taxi Ngurah Rai Bali 
Kotler, Philip. 2002. Manajemen Pemasaran, edisi millennium, jilid 1. Jakarta: PT. Prenhalindo.

Lambert, E. G., Hogan, N. L., \& Griffin, M. L. 2013. The impact Of Distributive \& Procedural Justice On Correctional Staff Job Stress, Job Satisfaction, \& Organizational Commitment. Journal of Criminal Justice, 3(5): h: 644 $-656$.

Lewis,R, Phillips, (2013). Keadilan Distributif, Keadilan Prosedural, Keadilan Interaksional, Kompensasi Dan Komitmen Karyawan. Jurnal Riset Manajemen dan Bisnis, 15(8): h: 500

Luthans. 1998.Organiational Behavior. Third Edition. New York: The McGrawHill Companies Inc.

Levinson, Sumbal, 2015. Manager's Leadership Style and Employess Job Satisfaction . Journal of Human and Social Science Research, 5(7): h: 134- 140.

Mangun, J. 2012. Evaluasi Kinerja Sumber Daya Manusia. Jakarta: Salemba Empat.

Miao, Ren tao. 2011. Perceived Organizational Support Job Satisfaction, Task Performance and Job OCB in China. Journal Instituted of Behaviorand Appied Management, 3(1): h: 105-127.

Muhhamad Meru dan Fajrianthi.2013. Pengaruh Keadilan organisasi terhadap intense turn over pada karyawan arsitek dan konstruktor di Surabaya. Jurnal psikologhi industry dan organisasi, 7(2): h: 261 - 267.

Nalendra, Evan. 2005. Pengaruh Kompensasi dan Motivasi Kerja terhadap Kepuasan Kerja Karyawan pada PT. Karya Sejati Vidyatama. Universitas Katolik Soegijapranata Semarang.Jurnal manajemen, 4(1): h: 205 - 211.

Paille, et al .2012. Examining the relationship among Job Satisfaction, Organizational Commitment, and Turnover Intention: An Emperical Study. International Journal Of Business and Management, 7(20): h: 4458 .

Puspitawati, Ni Made Dwi dan I, Gede , Riana. 2014. Pengaruh Kepuasan Kerja terhadap Komitmen Organisasional dan Kualitas Layanan. Jurnal Manajemen Strategi Bisnis dan Kewirausahaan, 8(1): h: 68-80.

Putra, A.A. Wisnu Yogeswara, dan Made, Surya , Putra,2014. Pengaruh Keadilan Organisasi pada Kepuasan Kerja Karyawan BPR Lestari. Jurnal Manajemen, 6(3): h: 30-38. 
Purba. 2014. Pengaruh Lingkungan Kerja terhadap Kinerja.Jurnal Manajemen, 6(1): h: $20-26$.

Rahmat Pima, dkk. 2002. "Pengaruh Lingkungan Kerja terhadap Kinerja Pegawai". Jurnal Administrasi Bisnis, 8(2): h: $24-30$.

Rhoades, L \& Eisenberger, R. 2002. Perceived Organizational Support : A Review Of Literature. Journal Of Applied Psychology, 87 (4) : 698 714.

Rivai, Veithzal. 2010. Manajemen Sumber Daya Manusia untuk Perusahaan . Jakarta : Raja Grafindo Persada.

Robbins, S.P., \& Judge, T.A. (2008). Perilaku Organisasi, Edisi 2. Penerbit Salemba Empat.

Robbins, Stephen P. 2012. Prinsip-prinsip Perilaku Organisasi. Jakarta: Erlangga.

Shanock, L.R. dan Eisenberger, R. (2016). When Supervisors Feel Supportet: Relationships With Subordinates ' perceived Supervisor Support, Perceived Organizational Support, and Performance. Journal of Applied Psychology, 93 (3): h: 689-695.

Sugiyono, V. 2014. Pengaruh Kepuasan Kerja dan Loyalitas Terhadap OCB karyawan PT Surya Timur Sakti Jawa Timur. Jurnal Manajemen, 1(1): h: 56-73.

Sutrisno, Herman. 2012. Manajemen Sumber Daya Manusia. Graha Ilmu. Yogyakarta

Tang, et al. 1996. Job Satisfaction, Organizational Commitment, Turnover Intention, \& Turnover : Path Analyses Based On Meta - Analytic Findings. Personnel Psychology, 46(12) : 259 - 293.

Umar, Muhammad, 2015. Filsafat John Rawls Tentang Teori Keadilan. Jurnal Psikologi, 19(1): h: 41-62. 